\title{
Opportunities for Improving Cancer Prevention at Federally Qualified Health Centers
}

\author{
Claire L. Allen • Jeffrey R. Harris • Peggy A. Hannon • \\ Amanda T. Parrish • Kristen Hammerback • John Craft • \\ Bruce Gray \\ Published online: 3 September 2013 \\ (C) The Author(s) 2013. This article is published with open access at Springerlink.com
}

\begin{abstract}
As the Affordable Care Act unfolds, federally qualified health centers (FQHCs) will likely experience an influx of newly insured, low-income patients at disparate risk for cancer. Cancer-focused organizations are seeking to collaborate with FQHCs and the Primary Care Associations (PCAs) that serve them, to prevent cancer and reduce disparities. To guide this collaboration, we conducted 21 interviews with representatives from PCAs and FQHCs across four western states. We asked about: $\mathrm{FQHC}$ priorities, barriers and facilitators to cancer prevention, the PCA-FQHC relationship, and collaboration opportunities for external organizations. FQHC priorities include medical home transformation, electronic health records, and clinical care; prevention efforts must integrate with these. Barriers to cancer prevention include competing priorities, inadequate patient insurance, and lack of reimbursement, while facilitators are the presence of patient navigators and cancer-related performance measures. Collaboration opportunities for external organizations include dissemination of culturally appropriate educational materials and support for patient navigators.
\end{abstract}

Keywords Cancer Prevention · Federally Qualified Health Center · Community Health Center · Primary Care Association

C. L. Allen $(\bowtie) \cdot J$. R. Harris • P. A. Hannon • A. T. Parrish •

K. Hammerback

University of Washington Health Promotion Research Center, 1107

NE 45th St., Suite 200, Seattle, WA 98105, USA

e-mail: claireallen1@gmail.com

J. Craft

Great West Division, American Cancer Society, 2120 1st Avenue N., Seattle, WA 98109, USA

B. Gray

Northwest Regional Primary Care Association, 6512 23rd Avenue NW., Suite 305, Seattle, WA 98117, USA

\section{Background}

Federally Qualified Health Centers (FQHCs) are communitybased organizations that provide comprehensive primary and preventive care to all people regardless of their ability to pay [1]. These health centers provide critical access to healthcare for those who are vulnerable to financial shocks and poverty. As of 2011, 72\% of FQHC patients had household incomes at or below the federal poverty level [2]. The Affordable Care Act of 2010 greatly expanded the role of FQHCs in caring for underserved populations by increasing direct, infrastructural support and by extending Medicaid coverage to low-income adults, regardless of their family status [3, 4]. Consequently, FQHCs will be increasingly important in providing a safety net for vulnerable populations.

The population served by $\mathrm{FQHCs}$ is at greater risk for many cancers and suffers worse outcomes when they do develop cancer [5]. FQHCs aim to improve cancer prevention, but studies show they need assistance in planning and implementing tobacco cessation treatment, screening for breast, cervical, and colorectal cancers, and reducing lifestyle-related risk factors (overweight/obesity and lack of physical activity) $[6,7]$.

Two system changes occurring in FQHCs across the country could help increase cancer prevention: Patient-Centered Medical Home (PCMH) transformation and Electronic Health Record (EHR) implementation. The medical home is a teambased care model led by a personal physician who provides continuous and coordinated care throughout a patient's lifetime to maximize health outcomes [8]. The PCMH could facilitate the delivery of preventive services through its emphasis on provider continuity, planned and coordinated care, and self-management support [9]. EHRs are a collection of health information on individual patients or populations that integrate information on demographics, medical history, medications, allergies, and test results across healthcare networks [10]. EHRs can lower health care costs, improve quality, and 
increase patient management of their own healthcare [11]. To expand EHR adoption, the Centers for Medicare and Medicaid Services created the EHR Meaningful Use Incentive Program [12]. Meaningful use of EHRs can benefit cancer prevention in FQHCs by creating registries that track patient populations, identifying appropriate preventive services for patients, and notifying providers when a patient is due to receive these services [13].

In addition to the PCMH and EHRs, the Human Resources and Services Administration (HRSA) also recently brought attention to cancer prevention. HRSA is the primary funder for FQHCs and requires them to report specific outcomes in their Uniform Data System (UDS) to maintain funding [14]. Prior to 2010, cervical cancer screening was the only cancer prevention measure FQHCs reported, but in the past 2 years, HRSA added body mass index documentation and follow-up for adults and children, tobacco cessation screening and counseling, and colorectal cancer screening [15]. The inclusion of these measures in the UDS increases the documentation and awareness of cancer prevention in FQHCs.

Though the PCMH model, EHRs, and cancer-related reportable measures have potential to advance cancer prevention, FQHCs face significant challenges in implementing these changes and need external support $[6,7,16]$. Primary Care Associations (PCAs) are membership organizations for FQHCs and provide advocacy, technical assistance, and training [17]. Though PCAs may be useful mediums for improving prevention and other health outcomes in FQHCs, the academic literature provides little insight into this relationship. External organizations interested in cancer prevention, like the American Cancer Society, are another potential source of support for FQHCs and want to learn how to best assist them, whether directly or through PCAs. The Great West Division of the American Cancer Society (GWDACS) asked the University of Washington's Health Promotion Research Center to conduct the study reported here to explore opportunities for GWDACS to collaborate with PCAs and FQHCs. The objectives were to determine current priorities for FQHCs, identify barriers and facilitators to cancer prevention, explore the PCA-FQHC relationship, and investigate opportunities for external organizations to work with FQHCs, both directly and through their PCAs, to increase cancer prevention.

\section{Methods}

Researchers conducted 21 interviews with PCAs and FQHCs in Colorado, Washington, Oregon, and Arizona. We chose these states because they are the largest four states in the GWDACS. Throughout data collection and analysis, we adhered to the Consolidated Criteria for Reporting Qualitative Research guidelines [18]. The University of Washington Institutional Review Board granted this study exempt status.
Study Sample

Researchers selected participants using purposive network sampling. To add depth to the data, we included interviews with representatives from $\mathrm{PCAs}$, FQHC systems, and $\mathrm{FQHC}$ clinics. We defined FQHC systems as the primary healthcare delivery site for the overarching organization and $\mathrm{FQHC}$ clinics as any of the satellite delivery sites which operate under the same organization name. Network sampling was necessary in this study because of the difficulty of reaching administrators in busy healthcare settings [19]. Researchers first interviewed representatives from the PCAs and at the end of each interview, the representatives recommended individuals from one rural FQHC system and one urban-focused $\mathrm{FQHC}$ system for an interview. Participants from the FQHC system interviews then recommended specific clinic representatives for interviews (see Fig. 1). Interviewees brought other colleagues into the conversation if they thought they would enrich the quality of the information provided in the interviews and therefore, we spoke with 30 individuals in 21 organization-level interviews. We captured the clinic-level perspective in six interviews, and 17 of our participants were clinicians, however, we were not able to conduct separate interviews at the clinic level in two cases: (1) when senior leaders invited a clinic-level person to their system-level interview and declined our request for an additional interview with only clinic-level personnel present, or (2) if senior leaders informed us that there was not a different perspective at the clinic level. Participants represented primarily quality directors at the PCA level, CEOs, and medical-directors at the FQHC system level, and clinic managers or nursing coordinators at the FQHC clinic level (see Table 1).

\section{Study Design and Procedures}

We developed a 16-item open-ended interview guide that covered several topics including: priorities, barriers and facilitators to cancer prevention, and the PCA-FQHC relationship (Interview guide available upon request). The guide disaggregated "cancer prevention" into three categories as follows: (1) tobacco cessation treatment, (2) screening for breast, cervical, and colorectal cancers, and (3) reduction of lifestyle-related risk factors. One experienced interviewer conducted the interviews by telephone conference call, while two to four other researchers recorded notes. Each interview lasted $1 \mathrm{~h}$ and was recorded and transcribed (Proof Positive Transcriptions, Garland, TX). We planned to interview a maximum of 25 organizations or until we reached the point at which we were no longer obtaining new knowledge (saturation). We discussed saturation throughout the interviewing period and agreed that we reached this point by the end of the study. 


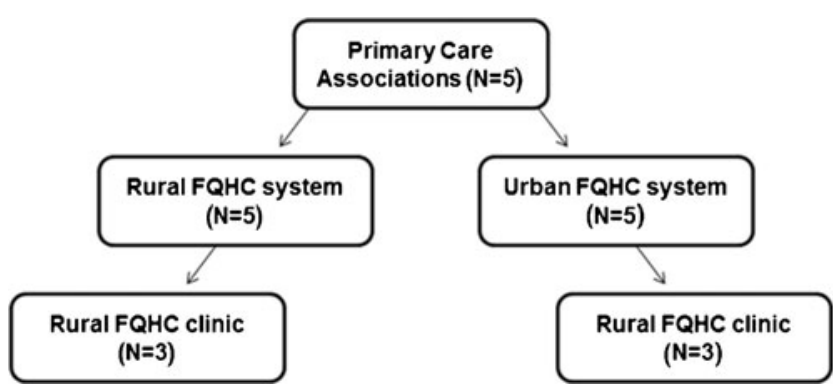

Fig. 1 Sampling strategy

Analysis

The methodology for this study was inductive content analysis. Inductive content analysis is a research technique in which themes emerge from raw data through repeated examination and is appropriate in qualitative research when there is not enough former knowledge of the subject to start from an established theoretical framework [20]. Using this methodology, the researcher derived a coding scheme from the data beginning with specific information and moving outward to broader, general categories [20]. Examples of coding categories were: priorities, PCA relationship, tobacco cessation, cancer screening, and lifestyle-related barriers and facilitators, PCMH, and EHR.

Two members of the team separately coded the transcripts. One data coder uploaded the transcripts into Atlas.ti version

Table 1 Participant characteristics

\begin{tabular}{lll}
\hline & Number & Percent (\%) \\
\hline Gender & 17 & 57 \\
$\quad$ Female & 13 & 43 \\
Male & & \\
Occupation & 7 & 23 \\
CEO & 5 & 17 \\
Director clinical services/quality & 4 & 13 \\
Human resources & 4 & 13 \\
Medical director & 6 & 20 \\
Nursing director/supervisor & 4 & 17 \\
Other & & \\
Organization & 9 & 30 \\
PCA & 9 & 30 \\
Rural FQHC system/clinic & 12 & 40 \\
Urban FQHC system/clinic & & \\
Location & 6 & 20 \\
Arizona & 9 & 23 \\
Colorado & 8 & \\
Oregon & 7 & \\
Washington & & \\
\hline
\end{tabular}

6.2 and two researchers coded the first $14 \%$ of the transcripts separately. The researchers then discussed any discrepancies in coding until they reached consensus. Both researchers proceeded to code another $14 \%$ of the transcripts and met again to discuss differences. Once the researchers reached consistent agreement, the primary data coder finished coding the remaining transcripts. The researcher then reviewed coded quotations for prevalent themes and reported results to the research team for discussion. After completing the analysis, as a check on validity, the researchers sent a summary of results to a participant who validated the interpretation of the information.

\section{Results}

We present the key themes below in three main categories: current priorities in $\mathrm{FQHCs}$, barriers and facilitators to cancer prevention in FQHCs, and the PCA-FQHC relationship and opportunities for collaboration.

\section{Current Priorities}

FQHCs and PCAs named several priorities, some of which come from the external healthcare environment which they have little control over, and some that are internal to their organization. Among PCAs, top priorities for helping FQHCs were to provide support for PCMH transformation and accreditation, and to provide technical assistance for EHR implementation so $\mathrm{FQHCs}$ can receive meaningful use incentives. Other top PCA priorities were reimbursement reform and workforce recruitment and retention. FQHCs prioritized acute, clinical work and basic resources, such as funding, space, and time. Every health center named diabetes as a top clinical priority. Rural FQHCs emphasized the need for basic resources more than urban-based health centers; however, it was clearly important for both. A rural participant explained, "In the food chain, the first priority is keeping the lights on, the second priority is keeping our patients happy, and then the third priority is actually health care." Neither FQHCs nor PCAs viewed cancer prevention as a high priority, but participants wanted to better integrate prevention into their health centers provided that it fit into existing routines (see Table 2).

\section{Barriers and Facilitators to Cancer Prevention in FQHCs}

FQHCs and PCAs identified a number of barriers and facilitators to cancer prevention in their health centers. The most common barrier in FQHCs was competing priorities. Participants from $\mathrm{FQHCs}$ noted it was nearly impossible to take on new tasks because scarce resources stretch staff to capacity. Additionally, the external pressures of PCMH transformation and EHR implementation are inundating FQHCs. This strain 
Table 2 Key quotes on $\mathrm{FQHC}$ priorities and barriers and facilitators to cancer prevention

\begin{tabular}{|c|c|c|}
\hline Topic & Key theme & Quotes \\
\hline \multirow[t]{2}{*}{$\mathrm{FQHC}$ priorities } & $\begin{array}{l}\text { Current top external priorities for FQHCs are PCMH } \\
\text { transformation and EHR implementation. }\end{array}$ & $\begin{array}{l}\text { "I think it's just keeping our heads above water in the pace of this change } \\
\text { that is the priority." } \\
\text { "The highest priority for assisting FQHCs is really with the } \\
\text { transformation taking place in healthcare, specifically the PCMH." }\end{array}$ \\
\hline & $\begin{array}{l}\text { Top internal priorities are diabetes and sustaining } \\
\text { basic resources. }\end{array}$ & $\begin{array}{l}\text { "Diabetes is always one that we focus on." } \\
\text { "In the food chain, the first priority is keeping the lights on." }\end{array}$ \\
\hline \multirow{3}{*}{$\begin{array}{l}\text { Barriers to cancer } \\
\text { prevention in } \\
\text { FQHCS }\end{array}$} & $\begin{array}{l}\text { Competing priorities amidst health care reform and } \\
\text { scarce time and resources are barriers in FQHCs. }\end{array}$ & $\begin{array}{l}\text { "I think that everyone feels really just overwhelmed with the number of } \\
\text { demands on their time." }\end{array}$ \\
\hline & $\begin{array}{l}\text { Patient insurance status is a primary barrier in FQHC } \\
\text { populations. }\end{array}$ & $\begin{array}{l}\text { "In a population of patients with no health coverage, preventative care for } \\
\text { the family usually takes a low priority." }\end{array}$ \\
\hline & $\begin{array}{l}\text { FQHCs named lack of reimbursement as a barrier to } \\
\text { lifestyle-related prevention. }\end{array}$ & $\begin{array}{l}\text { "We're living in a very encounter-based reimbursement scheme. A } \\
\text { cooking or exercise class... we're having to figure out how to fund that } \\
\text { on a shoestring." }\end{array}$ \\
\hline \multirow[t]{3}{*}{$\begin{array}{l}\text { Facilitators to cancer } \\
\text { prevention in } \\
\text { FQHCs }\end{array}$} & $\begin{array}{l}\text { FQHCs and PCAs thought of cancer prevention in } \\
\text { terms of the UDS outcome measures they report to } \\
\text { HRSA. }\end{array}$ & $\begin{array}{l}\text { "When HRSA says that we all have to do it, we all do it." } \\
\text { "A lot of our numbers are being driven by meaningful use or UDS } \\
\text { measures." }\end{array}$ \\
\hline & $\begin{array}{l}\text { Urban FQHCs named patient navigators or health } \\
\text { coaches as a facilitator to cancer prevention. }\end{array}$ & $\begin{array}{l}\text { "We try to model our patient navigation concept with all of them [cancer } \\
\text { screening, tobacco cessation, lifestyle-related prevention], because it } \\
\text { has proven to be really successful." } \\
\text { "We can see where a coach can spend } 15 \text { to } 20 \text { min when the provider } \\
\text { can't as really being effective." }\end{array}$ \\
\hline & $\begin{array}{l}\text { FQHCs in states with an active quit line named this as } \\
\text { a facilitator to tobacco cessation. }\end{array}$ & $\begin{array}{l}\text { "Our CHCs [FQHCs] are working very closely with the state quit line." } \\
\text { "I mean, the people use it [the quit line]. I've seen them using it. They } \\
\text { come in and ask for it." }\end{array}$ \\
\hline
\end{tabular}

leads to an overall lack of resources to focus on preventive care. PCAs and FQHCs commonly used the word "overwhelmed" to describe the current state of FQHCs. A second barrier FQHC participants stressed was the underinsurance of their patients. Without adequate insurance, their patients are not likely to pay for preventive care. Finally, participants named the present reimbursement system as a barrier to cancer prevention. FQHCs most often linked the lack of reimbursement to lifestyle-related prevention, emphasizing that they are not paid specifically for the time, space, and resources they put into exercise groups, cooking classes, or weight-management counseling. Rural centers experienced additional barriers of lack of patient transportation and access to services.

While there are many barriers to cancer prevention, $\mathrm{FQHCs}$ also named several things that make cancer prevention implementation more likely. Facilitators were required documentation of cancer-related UDS measures, patient navigators, and active quit lines for tobacco cessation. FQHCs and PCAs thought of cancer prevention primarily in terms of how it relates to the UDS measures FQHCs report to HRSA for funding. One participant stated, "We are doing smoking cessation because the federal government chose that as one of the clinical outcomes based on our HRSA UDS report. When HRSA says that we have to do it, we all do it." Another facilitator that all urban FQHCs mentioned was patient navigators. Urban FQHCs discussed a staff member who connects patients to preventive services and follows up with patients to remind them about upcoming healthcare needs. This team member had different position titles (patient navigator, patient aide, health coach), but the concept was the same. Finally, FQHCs thought quit lines were important for tobacco cessation among their patients. Quit lines are telephone-based tobacco cessation services offering treatment and counseling for addiction [21]. FQHCs in states with active quit lines (AZ, OR) named this as a facilitator, while states experiencing funding cuts to their quit lines (WA, CO), named these cuts as a barrier to cessation (see Table 2).

Participants expressed mixed feelings about EHRs. Overall, participants thought EHR systems were beneficial because they create reminders for preventive services and enable enhanced patient tracking and followup. Yet, other participants mentioned the complications of documenting preventive services and properly using EHR data for effective population management. Most agreed that EHRs are potentially helpful but have not yet realized that potential.

PCA-FQHC Relationship and Opportunities for Collaboration

Urban and rural FQHCs held different perceptions of the PCA-FQHC relationship. Urban FQHCs had regular 
interaction with their PCAs and had suggestions for how PCAs could better serve them, while most rural FQHCs were less aware of their PCAs. Urban FQHCs viewed the role of the PCA as sharing and disseminating best practices, providing training and educational materials, and lobbying and advocacy. Rural FQHCs emphasized their independence and thought PCA resources were not often applicable to their day-to-day clinical flow (see Table 3).

Despite these differences, both urban and rural health centers had similar suggestions for how external organizations might collaborate with them directly or through their PCAs. FQHCs thought culturally appropriate educational materials for patients in many languages would be helpful. Another suggestion for collaboration was continuing to share best practices. Best practices on how to improve cancer-related outcomes that FQHCs report in their UDS would be particularly useful. One rural participant stated, "We are struggling with how to improve our outcomes on those UDS measures, and we really don't have a good answer yet." Best practice materials should be aimed at providers and FQHC staff. As a distribution hub for FQHCs, PCAs could disseminate both patient- and provider-level materials to FQHCs. External organizations could also distribute these resources directly.

Urban FQHCs also suggested support for patient navigators as an opportunity for collaboration. Participants said financial backing of patient navigators is particularly important for $\mathrm{FQHCs}$ as it is difficult for them to add or shift staff without additional resources. External organizations could work through PCAs by supporting navigator training or could provide direct financial support to FQHCs. Both PCAs and FQHCs stressed that any efforts to improve cancer prevention should be integrated with PCMH transformation and EHR implementation, as well as with everyday clinical practice (see Table 3). FQHCs and PCAs perceived the PCMH and EHRs as opportunities to better integrate cancer prevention into their routines.

\section{Discussion}

This study investigated the state of cancer prevention in FQHCs and explored opportunities for organizations to work with FQHCs both directly and through their PCAs. We found that cancer prevention must integrate with PCMH transformation, EHR implementation, and existing clinical routines if it is to take hold, particularly given the stresses that health reform imposes on FQHCs. FQHCs are busy, resource-constrained, primary care settings, and additional underfunded responsibilities would be unwelcomed. Efforts to improve cancer prevention should align with related UDS measures that FQHCs already report to maintain funding status and with other established priorities. Though cancer prevention is not

Table 3 Key quotes on the PCA-FQHC relationship and opportunities to improve cancer prevention

\begin{tabular}{|c|c|c|}
\hline Topic & Key theme & Quotes \\
\hline \multirow[t]{3}{*}{ PCA-FQHC Relationship } & $\begin{array}{l}\text { Urban-based FQHCs thought PCAs served them } \\
\text { by sharing best practices, disseminating } \\
\text { information, and lobbying. }\end{array}$ & $\begin{array}{l}\text { "They [PCAs] do a lot of organizing and getting the different } \\
\text { centers together. Hopefully, we're sharing best practices } \\
\text { at those meetings." }\end{array}$ \\
\hline & $\begin{array}{l}\text { Rural-based FQHCs emphasized their } \\
\text { independence and noted that PCAs } \\
\text { were not often involved with internal } \\
\text { programs. }\end{array}$ & $\begin{array}{l}\text { "We don't see a lot of people from the PCA in our facilities, } \\
\text { nor does any other rural CHC [FQHC]." } \\
\text { "We're pretty independent folks. It would not go well for } \\
\text { someone to come in and tell us what we need to do." }\end{array}$ \\
\hline & $\begin{array}{l}\text { FQHCs did not know how PCAs relate to them } \\
\text { on cancer prevention, except indirectly } \\
\text { through the PCMH process. }\end{array}$ & $\begin{array}{l}\text { "Cancer screening and prevention has not been a high profile } \\
\text { initiative of the association, but more supported through } \\
\text { an overall approach to PCMH." }\end{array}$ \\
\hline \multirow{3}{*}{$\begin{array}{l}\text { Opportunities to improve } \\
\text { cancer prevention in } \\
\text { FQHCs }\end{array}$} & $\begin{array}{l}\text { FQHCs want culturally appropriate educational } \\
\text { materials that share best practices. }\end{array}$ & $\begin{array}{l}\text { "Educational materials in many languages would probably be } \\
\text { one of the areas that we could all be working on together better." }\end{array}$ \\
\hline & $\begin{array}{l}\text { Urban FQHCs need support for patient } \\
\text { navigators to guide patients towards } \\
\text { prevention. }\end{array}$ & $\begin{array}{l}\text { "They [patient navigators] would appreciate in-person training } \\
\text { on how to use the [cancer prevention] tools and how to } \\
\text { integrate them into the system." } \\
\text { "As far as the challenges go, it's just finding the infrastructure } \\
\text { to support this patient navigation concept." }\end{array}$ \\
\hline & $\begin{array}{l}\text { Cancer prevention efforts in FQHCs should } \\
\text { integrate with PCMH, EHRs, and routine } \\
\text { clinical flow. }\end{array}$ & $\begin{array}{l}\text { "If we were trying to do something to bump up cancer screening, } \\
\text { the carrot can be that this will help you to achieve your } \\
\text { meaningful use incentives." } \\
\text { "If they could be assessing what is needed in the health centers to } \\
\text { increase cancer screenings that matches, integrates, and dovetails } \\
\text { with this massive overarching PCMH, I think that would be really, } \\
\text { really helpful." }\end{array}$ \\
\hline
\end{tabular}


currently a top priority in FQHCs, this study identified ways to make it easier and more relevant to these health centers. Opportunities for external organizations to work with FQHCs to improve cancer prevention included providing culturally and linguistically relevant educational materials distributed directly or through the PCAs and support for patient navigators.

\section{Cancer Prevention Resources}

We found that culturally appropriate small media resources (videos, letters, brochures, flyers, etc.) in various languages could help improve cancer prevention in FQHCs. This finding is consistent with results from other studies. A systematic review of client-directed interventions to improve cancer screening performed by the Task Force for Community Preventative Services found that small media could improve cervical, breast, and colorectal cancer screening rates [22]. Small media are effective with many different populations including Hispanics, African-Americans, and women of low socioeconomic status and therefore, would also likely help FQHC populations [23].

Cancer prevention resources should align with the existing priorities of FQHCs. Every FQHC representative we interviewed named diabetes as a top clinical priority. Diabetes and several cancers share common behavioral risk factors including smoking, overweight/obesity, and inactivity. Resources focusing on health behaviors that reduce common risk factors would improve cancer prevention in a manner that fits with FQHC clinical priorities. Targeting health behaviors is also in line with the priorities of HRSA, the primary funder for FQHCs. HRSA added five UDS measures related to health behaviors and cancer prevention in the past 2 years. This motivates FQHCs to improve documentation of cancer prevention. Our finding that $\mathrm{FQHCs}$ think of cancer prevention primarily in terms of their UDS measures suggests that FQHCs are most likely to adopt cancer prevention resources that help them improve measurable outcomes, particularly those reported to maintain funding status.

The need for appropriate resources creates an opportunity for external organizations interested in cancer prevention to help FQHCs. As distribution hubs for member FQHCs, PCAs could disseminate prevention resources based on best practices. External organizations could support distribution through the PCAs or work with health centers directly. How organizations decide to support this effort may depend on the location of the health center. We found that rural FQHCs stressed their independence and believed that the current resources and work of PCAs primarily benefit urban health centers. This suggests that there are urban-rural differences in the PCA-FQHC relationship and that PCAs might consider new approaches for reaching out to rural health centers.

\section{Support for Patient Navigators}

This study found that staff at urban-based FQHCs believes designating patient navigators for specific prevention activities can facilitate cancer prevention. Evidence from other studies supports this finding. The Task Force for Community Preventive Services found that using patient navigators can reduce structural barriers to preventive screenings and the Guide to Community Preventive Services recommends that practices use navigators to increase cervical, breast, and colorectal cancer screenings [23, 24]. Patient navigation, supported by motivational interviewing, could also be a feasible way to increase preventive primary care visits for people who are overweight or obese [25]. PCAs that provide training to FQHCs could offer navigator training focused on cancer prevention. External organizations can support navigators by direct financial support to FQHCs or working through the PCAs. In this study, only urban-based FQHCs mentioned patient navigators as facilitators to prevention. While this could be because patient navigation is not needed in ruralbased FQHCs, an alternative explanation is that urban FQHCs have more funding and experience with patient navigation programs than rural health centers.

\section{Limitations and Strengths}

This study has three principal limitations and several strengths. The first limitation is that FQHCs provide primary care to diverse populations in a variety of settings and this study only sampled one region of the country. This limits the generalizability of these results; however, current priorities on national and state levels are the same for all $\mathrm{FQHC}$ systems and are likely affecting their ability to provide cancer prevention services in similar ways. Second, network sampling could create bias because each organization chose the interviewees. Network sampling is a qualitative technique used to access populations that are difficult to reach, and this sampling was essential for the researchers to learn the perspectives of senior leaders in FQHCs. A third limitation is that researchers could not always conduct separate interviews at the clinic level. This suggests that the study may not have captured the clinic perspective as thoroughly as it obtained the FQHC system perspective.

Despite these limitations, this study also has several strengths. The design of this study allowed researchers to gain deeper understanding of the FQHC environment by interviewing a variety of occupational positions across several organizations. While there are a few case studies in which FQHCs and PCAs work together on cancer prevention, this is the first study in the academic literature to explore the PCAFQHC relationship and cancer prevention across several organizations $[16,17]$. This is also the first study to capture and 
compare perspectives on cancer prevention from representatives in both urban and rural FQHCs.

\section{Conclusion}

The PCMH model, EHRs, and cancer-related UDS measures create opportunities to increase cancer prevention, yet implementation of these changes in the midst of health reform poses real challenges for $\mathrm{FQHCs}$, especially those in the rural areas. External organizations hoping to support FQHCs must understand the overwhelming demands of the FQHC setting and integrate assistance into existing priorities and routines. $\mathrm{Pa}-$ tient navigators and culturally relevant educational materials that focus on improving reportable outcomes are important ways to increase cancer prevention. However, adding staff or responsibilities to under-resourced $\mathrm{FQHCs}$ requires crucial financial support. External organizations can collaborate with FQHCs either directly or through their state and regional PCAs to improve cancer prevention outcomes for high-risk populations.

This study explored the relationship between PCAs and FQHCs and the findings suggest potential opportunities to increase cancer prevention in the era of health reform. As the Affordable Care Act unfolds, further studies should identify specific ways in which cancer prevention can integrate with the broader PCMH and EHR movements in FQHCs. Studies testing the feasibility of the PCA as a medium for improving health outcomes in FQHCs would further elucidate the mechanisms through which these organizations relate and could extend the potential reach of health interventions supported by external organizations wanting to work with FQHCs.

Acknowledgments Research efforts were supported by the Great West Division of the American Cancer Society. HPRC is funded in part by the Centers for Disease Control and Prevention, Prevention Research Centers Program, through the University of Washington Health Promotion Research Centers Cooperative Agreement U48DP001911. The contents of this work are solely the responsibility of the authors and do not necessarily represent the official views of the Centers for Disease Control and Prevention.

Open Access This article is distributed under the terms of the Creative Commons Attribution License which permits any use, distribution, and reproduction in any medium, provided the original author(s) and the source are credited.

\section{References}

1. Doty MM, Abrams MK, Hernandez SE, Stremkikis K, Beal AC (2010) Enhancing the capacity of community health centers to achieve high performance: findings from the 2009 Commonwealth Fund National Survey of Federally Qualified Health Centers. The Commonwealth Fund. http://www.commonwealthfund.org/ Publications/Fund-Reports/2010/May/Enhancing-the-Capacity-of-
Community-Health-Centers-to-Achieve-High-Performance. Accessed 12 April 2013

2. National Association of Community Health Centers (2011) America's Health Centers. http://www.nachc.com/client// America's $\% 20$ Health $\% 20$ Centers $\% 20$ Fact $\% 20$ Sheet $\% 20$ August $\%$ 202011.pdf. Accessed 13 April 2013.

3. Axelroda DA, Millman D, Abecassis MM (2010) US health care reform and transplantation, part II: impact on the public sector and novel health care delivery systems. Am J Transplant 10: 2203-2207

4. Bailey P, Osberg B (2011) Health Care Reform: Opportunities and Challenges Facing FQHCs. http://www.nwrpca.org/health-centernews/203-health-care-reform-opportunities-and-challenges-facingfqhcs.html. Accessed 10 April 2013.

5. Ward E, Jemal A, Cokkinides V, Singh GK, Cardinez C, Ghafoor A, Thun M (2004) Cancer disparities by race/ethnicity and socioeconomic status. CA Cancer J Clin 54(2):78-93

6. Cialdella-Kam L, Sabado P, Bispeck K, Silverman S, Bernstein L et al (2012) Implementing cancer prevention into clinical practice. J Cancer Educ 27(2):S136-S143

7. Taplin SH, Haggstrom D, Jacobs T, Determan A, Granger J, Montalvo W, Snyder WM, Lockhart S, Calvo A (2008) Implementing colorectal cancer screening in community health centers: addressing cancer health disparities through a regional cancer collaborative. Med Care 46:S74-S83

8. Patient-centered Primary Care Collaborative (2012) Joint Principles of the Patient-Centered Medical Home. http://www.acponline.org/ running_practice/pcmh/demonstrations/jointprinc_05_17.pdf. Accessed 12 March 2013

9. Sarfaty M, Wender R, Smith S (2009) Promoting cancer screening within the patient centered medical home. CA Cancer J Clin 61(6):397-408

10. Gunter TD, Terry NP (2005) The emergence of national electronic health record architectures in the United States and Australia: models, costs, and questions. J Med Internet Res 7:1

11. Centers for Disease Control and Prevention (2012) Meaningful Use Fact Sheet. http://www.cdc.gov/phin/library/PHIN_Fact_Sheets/FS MU_RLR_2012_5_21.pdf. Accessed 26 May 2012.

12. Blumenthal D (2010) Launching HITECH. N Engl J Med 362(5):382-385

13. Poon EG, Wright A, Simon SR, Jenter CA, Kaushal R, Volk LA, Cleary PD, Singer JA, Tumolo AZ, Bates DW (2010) Relationship between use of electronic health record features and health care quality: results of a statewide survey. Med Care 48(3):203-209

14. Health Resources and Services Administration, Bureau of Primary Health Care (2008) Health Centers: America's Primary Care Safety Net, Reflections on Success, 2002-2007. http://www.hrsa.gov. offcampus.lib.washington.edu/ourstories/healthcenter/reflec tionsonsuccess.pdf. Accessed 28 June 2011

15. Human Resources and Services Administration, Bureau of Primary Health Care (2012) Clinical and Financial Performance Measures. http://bphc.hrsa.gov/policiesregulations/performancemeasures/. Accessed 20 April 2012

16. Martinez-Gutierrez J, Jhingan E, Angulo A, Jimenez R, Thompson B, Coronado GD (2012) Cancer screening at a federally qualified health center: a qualitative study on organizational challenges in the era of the patient-centered medical home. J Immigr Minor Health. [In press]

17. Friedman DB, Young VM, Freedman DA, Adams SA, Brandt HM, Xirasagar S, Felder TM, Ureda JR, Hurley T, Khang L, Campbell D, Hébert JR (2012) Reducing cancer disparities through innovative partnerships: a collaboration of the South Carolina Cancer Prevention and Control Research Network and Federally Qualified Health Centers. J Cancer Educ 27(1):59-61

18. Tong A, Sainsbury P, Craig J (2007) Consolidated criteria for reporting qualitative research (COREQ): a 32-item checklist for interviews and focus groups. Int J Qual Health Care 19(6):349-357 
19. Miles M, Huberman A (1994) Qualitative data analysis. Thousand Oaks, California

20. Elo S, Kyngäs H (2008) The qualitative content analysis process. J Adv Nurs 62(1):107-115

21. Centers for Disease Control and Prevention (2004) Telephone Quitlines: A Resource for Development, Implementation, and Evaluation. http://www.cdc.gov/tobacco/quit_smoking/cessation/ quitlines/index.htm. Accessed 10 April 2013

22. Baron RC, Rimer BK, Breslow RA, Coates RJ, Kerner J, Melillo S, Habarta N, Kalra GP, Chattopadhyay S, Wilson KM, Lee NC, Mullen PD, Coughlin SS, Briss PA, Task Force on Community Preventive Services (2008) Client-directed interventions to increase community demand for breast, cervical, and colorectal cancer screening: a systematic review. Am J Prev Med 35:S34 S55
23. Sabatino SA, Lawrence B, Elder R, Mercer SL, Wilson KM, DeVinney B, Melillo S, Carvalho M, Taplin S, Bastani R, Rimer BK, Vernon SW, Melvin CL, Taylor V, Fernandez M, Glanz K, Community Preventive Services Task Force (2012) Effectiveness of interventions to increase screening for breast, cervical, and colorectal cancers: nine updated systematic reviews for the guide to community preventive services. Am J Prev Med 43(1):97-118

24. Wells KJ, Battaglia TA, Dudley DJ, Garcia R, Greene A, Calhoun E, Mandelblatt JS, Paskett ED, Raich PC (2008) Patient navigation: state of the art or is it science? Patient Navigation Research Program. Cancer 113(8): 1999-2010

25. Battaglia TA, McCloskey L, Caron SE, Murrell SS, Bernstein E, Childs A, Jong H, Walker K, Bernstein J (2012) Feasibility of chronic disease patient navigation in an urban primary care practice. J Ambul Care Manage 35(1):38-49 